\title{
Designing Entertainment for the Aging Population
}

\author{
Paula Alexandra Silva ${ }^{1}$ and Masood Masoodian ${ }^{2}$ \\ 1 DigiMedia Research Center, University of Aveiro, Portugal \\ palexa@gmail.com \\ 2 School of Arts, Design and Architecture, Aalto University, Finland \\ masood.masoodian@aalto.fi
}

\begin{abstract}
Despite the ever-increasing aging world population, most interactive entertainment and fun technologies are not specifically being designed for older adults. However, this trend is starting to change, particularly in the area of entertainment for health and wel-being. Therefore, this workshop aims to bring together researchers, designers, developers and entrepreneurs interested in the design, development, evaluation, commercialization and deployment of entertainment technologies for the aging population, targeting their needs and promoting their health and well-being.
\end{abstract}

Keywords: Aging population · older adults · entertainment for aging · design for aging · health · well-being.

\section{Background}

The world population is aging [3]. It is estimated that by $2040,21.7 \%$ of the population of the United States [4], and by $2070,42 \%$ of the population of the European Union [1] will be over 65 years old. It is, therefore, becoming ever more important to design products and services to better accommodate for the needs, requirements, expectations and characteristics of older adults.

Health and healthy living is clearly important to us humans, and we all want to have healthy and active lives which we can enjoy for as long as possible. In this context, it is not surprising that an increasing number of interactive tools and technologies are being developed to support us in this regard. Many of these interactive tools and technologies also tend to rely on our desire to have fun and be entertained, while working towards achieving a longer, active, and healthy life, in which we meet our goals, needs and desires.

Unfortunately, most such interactive entertainment and fun tools for health and well-being have not been designed specifically for an aging population. This is perhaps due to a misperception that older adults are not, or have not been in the past, very technologically able. In reality, however, analysts point out that it is indeed a misperception that "the $50+$ are technologically challenged and unplugged. In fact, aging consumers are tech savvy and eager for more." [2]. 
This myth is slowly being demystified with innovative, multidisciplinary, collaborative, and user-led approaches becoming more and more common. Arguably, by following such interdisciplinary approaches, we will better design for fun, engaging, inclusive, and entertaining technologies that reward the longevity that us humans have conquered.

Despite the importance of research into design of entertainment technology targeting older adults, there are not many opportunities for researchers and practitioners to meet and discuss their interests and ideas. This workshop aims to provide such a forum, enabling researchers and practitioners to share learnings and experiences related to design, development, evaluation, and deployment of entertainment tools and technologies for the ageing population.

\section{Objectives}

The main objective of this workshop is to bring together researchers, designers, developers and entrepreneurs interested in the design, development, evaluation, commercialization and deployment of entertainment tools and technologies for the aging population, targeting their needs and desire, and promoting their health and well-being.

Further to this, the workshop aims to create links between interested parties, and to encourage them to collaborate across disciplines and professional boundaries. We also hope that this workshop will be the first in a series of future workshops, which will become a forum for gathering of participants interested in entertainment technologies of the aging population.

\section{Contributions}

To achieve the above objectives, we invited researchers and practitioners from related backgrounds to submit their papers reporting their contributions to the topics of the workshop. Topics of interest included: healthy living, rehabilitation, prevention, active aging, independent living, person-centred approaches, connected health, quality of life and well-being. We sought submissions related to the following areas:

- Design, development, and evaluation of fun and entertainment technologies for the aging population.

- Acceptability and adoption of fun and entertainment technologies by the aging population.

- Examples and case studies of fun and entertainment technologies for the aging population.

- Innovative approaches to the design, development, evaluation, and commercialization of fun and entertainment technologies for the aging population.

- Community- and user-led innovations in fun and entertainment technologies for the aging population.

- Participatory and co-design methodologies and approaches for smart, active, and healthy aging. 


\section{Expected Outcomes}

In addition to sharing and generating ideas amongst its participants, through a planned discussion session, this workshop will investigate potential future outcomes. These may include a special issue of an international journal and/or a co-authored report for dissemination of the workshop findings.

Furthermore, the accepted workshop papers have been published in this conference proceedings. We will also make the accepted papers and presentations available on the workshop website ${ }^{3}$, which has been created for publicizing its aims and objectives, and disseminating its outcomes.

\section{Workshop Programme}

Our aim is to make this workshop as engaging and participatory as possible by including plenty of time for discussions and exchange of ideas. The workshop will achieve this aim through the inclusion of:

- Short presentations of the accepted papers.

- A follow-up interactive session to allow further discussions.

- A collaborative design activity.

- Concluding discussions and planning of future directions and outcomes.

\section{Workshop Organizers}

Dr. Paula Alexandra Silva is a Human-Computer Interaction (HCI) researcher and practitioner whose passion is to understand how to leverage technology to create a better future for us all. She has earned her Ph.D. in Computer Science from the University of Lancaster, United Kingdom. Since finishing her Ph.D. she focuses on designing applications for older adults with a view to improve their overall health and well-being and enable their active participation in society. She is also a passionate teacher who strives to create exceptional learning experiences for her students. She is currently a Research Fellow in the University of Aveiro. Before she held appointments as lecturer at a number of universities, as Postdoc Fellow at the University of Hawai'i and as Senior Scientist at Fraunhofer Portugal, where she managed the Human-Computer Interaction area and group.

Prof. Masood Masoodian leads the Aalto Visual Communication Design (AVCD) research group at Aalto University, Finland. He has a Ph.D. from the University of Waikato, New Zealand. His research interests include visualization, interactive media, and interaction design, with particular interest in designing interactive visualizations to provide effective means of understating information by ordinary people in areas such as health, energy, and sustainability. He is also

\footnotetext{
${ }^{3}$ http://avcd.aalto.fi/deap2018/
} 
actively involved in research related to different aspect of designing for older adults, including emotional design for entertainment, health and well-being. Prof. Masoodian has served as the programme chair, programme committee member, and reviewer for many international conferences and scientific journals. He has also been a co-organizer of several international conferences and workshops.

\section{Programme Committee}

Sergi Bermúdez i Badia (Universidade da Madeira, Portugal), Leah Burns (Aalto University, Finland), Masood Masoodian (Aalto University, Finland), Francisco Nunes (Fraunhofer - AICOS, Portugal), Thomas Rist (University of Applied Sciences Augsburg, Germany), Rita Santos (Universidade de Aveiro, Portugal), Paula Alexandra Silva (Universidade de Aveiro, Portugal), Ana Veloso (Universidade de Aveiro, Portugal).

\section{References}

1. European Union: The 2018 ageing report (2017), https://ec.europa.eu/info/ sites/info/files/economy-finance/ip065_en.pdf, [Accessed in July 2018]

2. Irving, P., Chatterjee, A.: The longevity economy: From the elderly, a new source of economic growth (2013), http://www.milkeninstitute.org/publications/view/ 687, [Accessed in July 2018]

3. United Nations Department of Economic and Social Affairs Population Division: World population ageing (2015), http://www.un.org/en/development/desa/ population/publications/pdf/ageing/WPA2015_Report.pdf, [Accessed in July 2018]

4. United States Department of Health and Human Services: 2017 profile of older Americans (2018), https://www.acl.gov/aging-and-disability-in-america/ data-and-research/profile-older-americans, [Accessed in July 2018] 